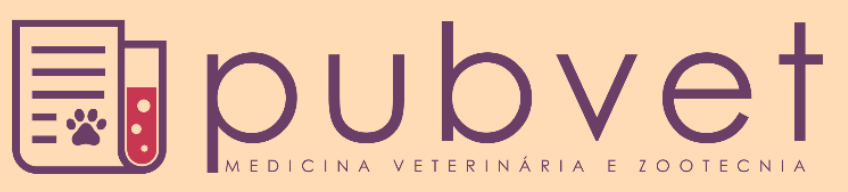

https://doi.org/10.31533/pubvet.v13n9a411.1-4

\title{
Onicodistrofia lupóide simétrica canina como manifestação da psora latente: Relato de caso
}

\author{
Cidéli de Paula Coelho ${ }^{1 \bullet}$, Adalberto do Carmo Braga von Ancken ${ }^{2 *} \bullet$ \\ ${ }^{1}$ Professora e pesquisadora UNISA (Departamento de pós-graduação), HD Science (Especialização em Homeopatia Veterinária). São Paulo - sp, Brasil. \\ ${ }^{2}$ Doutorando UNIP (Departamento de pós-graduação); HD Science (Especialização em Homeopatia Veterinária). São Paulo - sp, Brasil. \\ *Autor para correspondência, E-mail: acbvonancken@hotmail.com
}

Resumo. A onicodistrofia lupóide simétrica (OLS) é uma patologia imunomediada rara com origem idiopática e que pode acometer os cães. O diagnóstico diferencial inclui dermatites fúngicas, bacterianas, autoimunes e neoplasias. $\mathrm{O}$ exame histopatológico é o principal método diagnóstico, requerendo a amputação da terceira falange. Não há predisposição por raças e a idade dos cães acometidos costuma variar entre 3 e 8 anos de idade. $\mathrm{O}$ tratamento clínico pode levar até 6 meses para demonstrar algum efeito e o prognóstico é reservado. A homeopatia visa o bem-estar do paciente e a evolução miasmática precisa ser compreendida para avaliação do prognóstico de cura. Este artigo relata o caso clínico de uma cadela com alterações físicas e comportamentais que, ao ser tratada com medicamento homeopático selecionado pela lei de semelhança (Simillimum), apresentou a OLS como manifestação psórica e, posteriormente, chegou ao seu patamar de cura. A homeopatia figura como grande opção para o tratamento desta enfermidade.

Palavras-chave: homeopatia, medicina integrativa, pododermatite, ultradiluição

\section{Canine Symmetrical Lupoid Onycodystrophy as latent psora expression: case report}

Abstract. Symmetrical Lupoid Onycodystrophy (SLO) is a unusual immuno-mediated pathology with idiopathic etiology that can affect canine species. Differential diagnosis includes fungal, bacterial and autoimmune dermatitis and neoplasia. Histopathology is the main diagnostic technique, although it demands on the distal phalanx amputation. There are no predispositions regarding to dog's breeds and the age of ill dogs can be from 3 to 8 years old. Clinical management can take up to six months to show some effect and has a uncertain prognosis. Homeopathy aims to patient well-being and miasm dynamics must be comprehended in order to set a correct prognosis evaluation. This article reports a canine clinical case with physycal and behavioural disturbances which, treated by its Simillimum (high-diluted medicine chosen by the similia principle), expressed the SLO as a latent psora manifestation and reached a cure status later. Homeopathy figure out as a great option to treat this illness condition.

Keywords: Homeopathy, integrative medicine, pododermatitis, high dilution

\section{Onicodistrofia lupoide simétrica canina como manifestación de psora latente: reporte de un caso}

Resumen. El onicomodistrofia lupoide simétrico (OLS) es una patología inmunomediada rara con origen idiopático que puede afectar a los perros. El diagnóstico diferencial incluye dermatitis fúngicas, bacterianas, autoinmunes y neoplasias. El examen histopatológico es 
el método de diagnóstico principal, que requiere la amputación de la tercera falange. No hay predisposición para las razas y la edad de los perros afectados generalmente varía entre los 3 y los 8 años. El tratamiento clínico puede demorar hasta 6 meses para demostrar algún efecto y el pronóstico es reservado. La homeopatía apunta al bienestar del paciente y la evolución miasmática necesita ser entendida para evaluar el pronóstico de la cura. Este artículo informa el caso clínico de una perra con alteraciones físicas y de comportamiento que, cuando tratada con medicina homeopática seleccionada por la ley de similitud, reveló OLS como una manifestación psórica y, más tarde, alcanzó su nivel de curación. La homeopatía es una excelente opción para el tratamiento de esta enfermedad.

Palabras clave: homeopatía, medicina integral, pododermatitis, ultra dilución

\section{Introdução}

A onicodistrofia lupóide simétrica (OLS) é uma patologia imunomediada com origem idiopática e que acomete os cães (Palumbo et al., 2010). As unhas caem e renascem com sintomas (Ziener \& Nødtvedt, 2014) como onicalgia, onicodistofia, melanoníquia, onicólise, onicorrexe, onicomadesia e xerose no tecido adjacente (Mueller et al., 2004; Solomon et al., 2009) de todas as unhas.

O diagnóstico diferencial inclui dermatites fúngicas, bacterianas, auto-imunes e neoplasias (Silva et al., 2018). A histopatologia da falange distal acusa degeneração hidrópica da camada basal do epitélio e dermatite de interface liquenóide com amplo infiltrado de células inflamatórias (Solomon et al., 2009). Não há predisposição por raças e a idade dos cães acometidos costuma variar entre 3 e 8 anos de idade (Ziener \& Nødtvedt, 2014). As terapias comumente empregadas são prescritas de forma contínua, levando até seis meses (Ziener \& Nødtvedt, 2014) para obter algum resultado devido ao confinamento anatômico das lesões e com prognóstico clínico reservado.

O tratamento homeopático visa o equilíbrio entre mente e corpo e físico, sendo que os medicamentos são prescritos com base no principal pilar desta ciência: a lei de semelhança. Segundo o criador da homeopatia Samuel Hahnemann, semelhante cura semelhante e, assim, um medicamento é escolhido com base nas alterações que pode causar em um indivíduo sadio (Pustiglione, 2010). Dessa forma, o princípio da similitude age em organismos doentes e proporciona um processo de cura que expõe mudanças, tanto físicas quanto mentais, neste caminho rumo à psora, o miasma objetivo do homeopata. Este artigo descreve o caso clínico de uma cadela com OLS tratada com homeopatia.

\section{Relato de caso}

Foi atendido em junho de 2018 em uma clínica veterinária da cidade de São Paulo, um canino da raça West Highlang White Terrier, fêmea, quatro anos de idade, com histórico de gastroenterite crônica. O exame de ultrassom revelou inflamação intestinal no cólon e aumento da silhueta hepática com elevação difusa de ecogenicidade. A escolha dos principais sintomas mentais é traduzida em linguagem denominada repertorial e elencou os seguintes sintomas: duro com subordinados e amável com superiores;covardia; ditatorial; fígado, inflamação; estômago, afecções e reto, diarreias. Foi receitado Lycopodium clavatum $30 \mathrm{cH}$, bid.

Após 60 dias, os tutores relataram uma grande mudança no comportamento da cadela, classificando sua relação com todos os membros da residência como excelente, inclusive com atitudes que há muito não demonstrava. Também não apresentou episódios posteriores de êmese e diarréia. Estava disposta, se alimentando e dormindo bem, o que foi impreterível para a manutenção da medicação. Em outubro de 2018 os tutores retornaram em consulta alegando que apesar da nítida melhora comportamental, a cadela agora apresentava dor nas patas com claudicação e todas as suas unhas estavam esfarelando.

Ao exame físico foi possível observar onicalgia à manipulação, inflamação do tecido ungueal, onicorrexe, onicomadese e onicodistrofia em todos os 20 dígitos (Figura 1). Foi prescrito Sulphur $6 \mathrm{cH}$, bid e encaminhado uma amostra da unha para exame histopatológico. Após um mês, a cadela já não apresentava dor e nem claudicava, mas suas unhas ainda esfarelavam. Assim, Silicea $6 \mathrm{cH}$, bid por 30 dias foi o tratamento prescrito. Após 60 dias as unhas apresentavam-se íntegras e compactas com o tecido adjacente sem inflamação (Figura 2). 


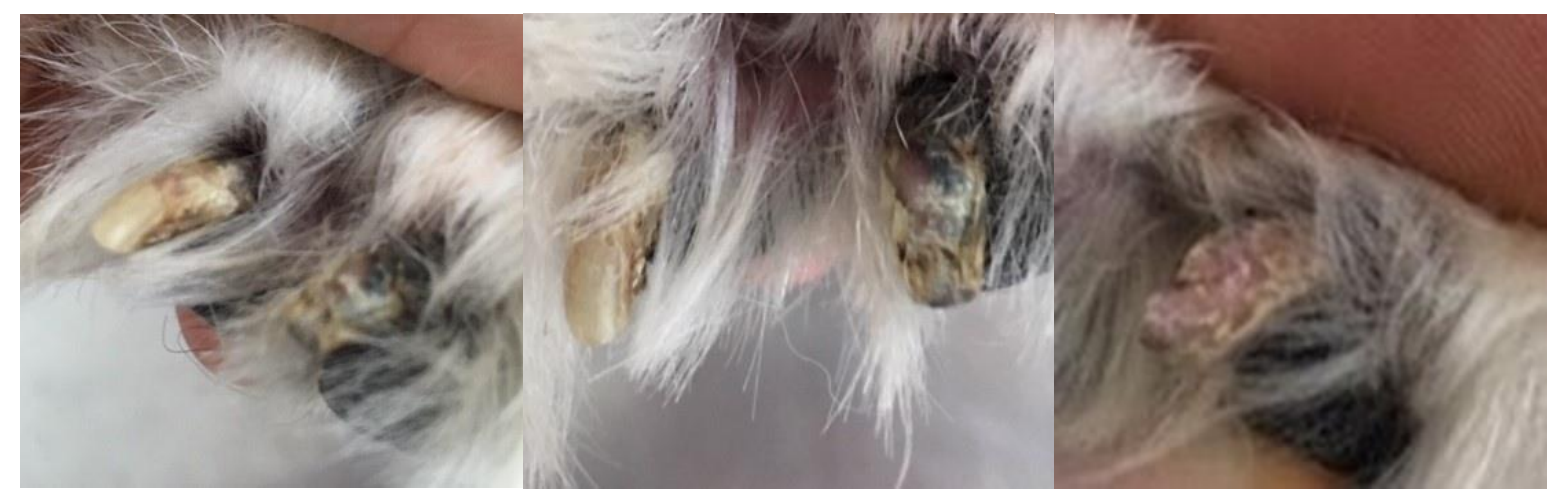

Figura 1. Onicomadese, onicorrexe e onicodistrofia das unhas.

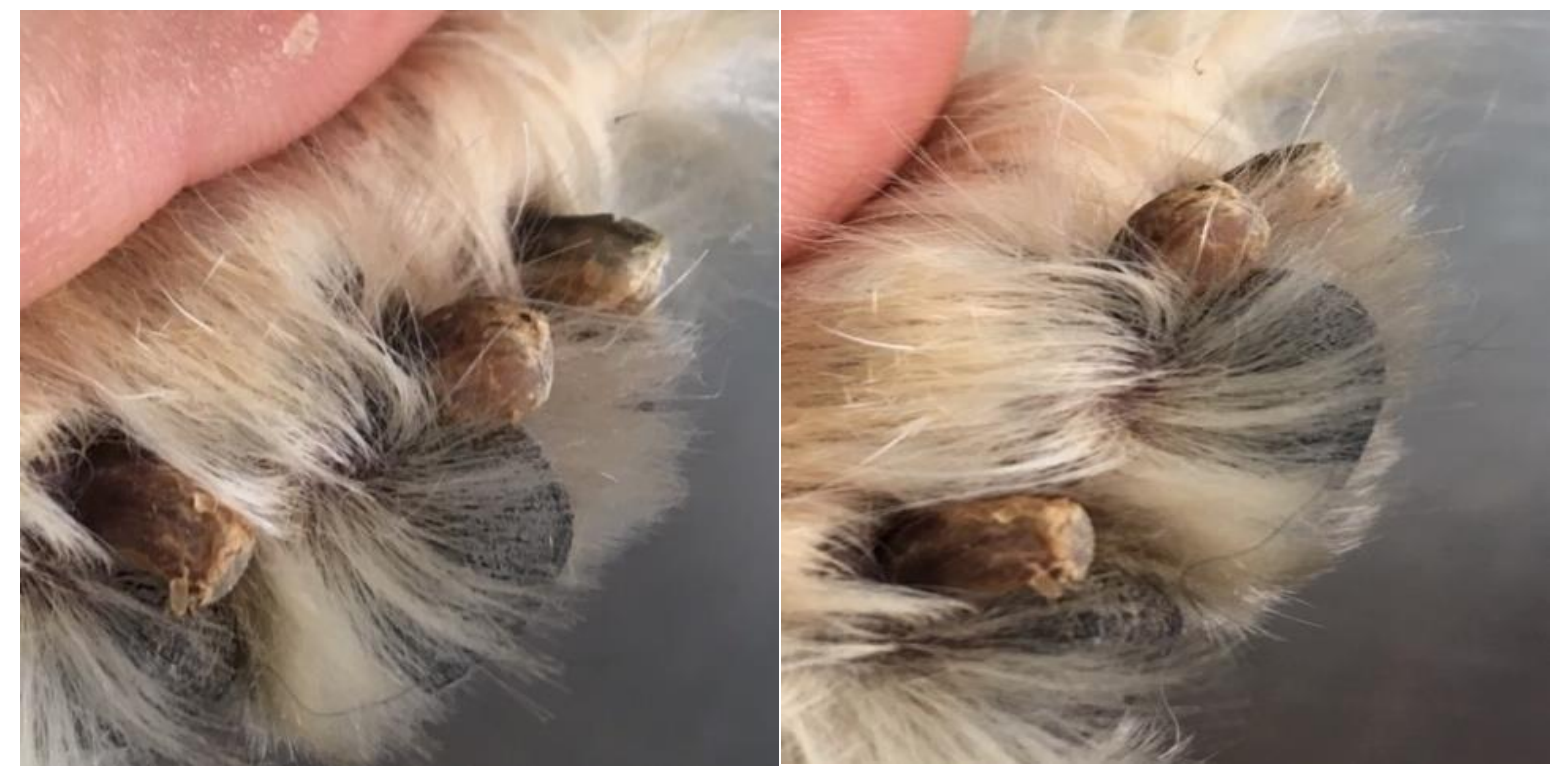

Figura 2. Unhas após tratamento com Sulphur e Silicea.

\section{Discussão}

Condições que afetam apenas as unhas são incomuns como manifestações de doença dermatológica (Auxilia et al., 2001). A necessidade de amputação do dígito é um fator limitante para o diagnóstico desta patologia (Verde \& Basurco, 2000); porém, não foi necessária neste caso em que a completa recuperação macroscópica das unhas e do tecido ungueal possibilitou o retorno funcional do membro.

A análise histopatológica das unhas demonstrou agregado de células inflamatórias acompanhadas de moderadas estruturas cocóides (bactérias) e ausência de fungos. A inexistência do histórico clínico de dermatopatias foi determinante na exclusão de processos cutâneos imunomediados como atopia e hipersensibilidade, além da OLS ser a única perturbação que causa desprendimento agudo de todas ou da maioria das unhas (Power \& Prélaud, 2011).

Drogas que visam à imunossupressão como corticosteroides sistêmicos, azatioprina, pentoxifilina, ciclosporina, antibioticoterapia e ácidos graxos (Auxilia et al., 2001; Mueller et al., 2003) são comumente empregadas no tratamento desta patologia e revezam-se conforme a necessidade do paciente. O medicamento homeopático é selecionado de acordo com a lei de semelhança, o que garante a prescrição segundo a individualidade do paciente e o tratamento do doente e não da doença.

A evolução miasmática é um importante fator que deve ser considerado na reavaliação de um paciente em busca da segunda prescrição do medicamento homeopático.

$\mathrm{Na}$ consulta inicial, o paciente encontrava-se no miasma sicose com hiperfunção de órgãos (inflamação intestinal com diarreia), além da evidente hipertrofia de ego manifestada pelo ditatorialismo. Lycopodium clavatum conduziu o paciente à psora, miasma caracterizado por 
manifestações de exteriorização como a inflamação ungueal e a fragilidade das unhas. Este processo foi completamente controlado por Sulphur e Silicea, medicamentos do modo reacional psórico.

\section{Conclusão}

A presença de bem-estar, traduzido por hábitos fisiológicos normais (alimentação, excreções, sono) e a boa disposição permite classificar este paciente no miasma psórico, cuja manifestação latente foi remediada pela segunda prescrição. A exteriorização de sintomas em concordância com as leis de cura também pode ser inoportuna, neste caso deformando fâneros e causando dor e claudicação. A aplicação da lei de semelhança torna a homeopatia uma opção considerável para o tratamento desta enfermidade.

\section{Referências bibliográficas}

Auxilia, S. T., Hill, P. B. \& Thoday, K. L. (2001). Canine symmetrical lupoid onychodystrophy: a retrospective study with particular reference to management. Journal of Small Animal Practice, 42(2):82-87.

Mueller, R. S., Rosychuk, R. A. \& Jonas, L. D. (2003). A retrospective study regarding the treatment of lupoid onychodystrophy in $30 \mathrm{dogs}$ and literature review. Journal of the American Animal hospital Association, 39(2):139-150.

Mueller, R. S., West, K. \& Bettenay, S. V. (2004). Immunohistochemical evaluation of mononuclear infiltrates in canine lupoid onychodystrophy. Veterinary Pathology, 41(1):37-43.

Palumbo, M. I. P., Machado, L. H. A., Soares, L. M., Torres Neto, R., Fabris, V. E., Lourenço, M. L. G. \& Vailati, M. d. C. F. (2010). Onicodistrofia lupoide simétrica canina: relato de caso. Clínica Veterinária, 15(8):48-52.

Power, H. \& Prélaud, P. (2011). The role of breed in canine skin disease. Veterinary Focus, 21(3):1017.

Pustiglione, M. (2010). O organon da arte de curar de Samuel Hahnemann para os ,culo 21: Organon.

Silva, L. F., Blume, G. R., Eloi, R. S. A., Lemos, J. A., Silva, A. S., Lorenzo, C., . . Sant'Ana, F. J. F. (2018). Alterações neoplásicas e não neoplásicas das mãos e dos pés de cães (2003-2016). Pesquisa Veterinária Brasileira, 38(7):1394-1404.

Solomon, S. E. B., Friesen, R., de Farias, M. R., Werner, J., Caron, V. \& Soresini, G. C. G. (2009). Oniquite lupóide isolada em cão: Relato de Caso. 7, 23(467-469).

Verde, M. T. \& Basurco, A. (2000). Symmetrical lupoid onychodystrophy in a crossbred pointer dog: long-term observations. Veterinary Record, 146376-378.

Ziener, M. L. \& Nødtvedt, A. (2014). A treatment study of canine symmetrical onychomadesis (symmetrical lupoid onychodystrophy) comparing fish oil and cyclosporine supplementation in addition to a diet rich in omega-3 fatty acids. Acta Veterinaria Scandinavica, 56(1):66.

Recebido: 19 de julho de 2019

Aprovado: 8 de agosto, 2019.

Publicado: 31 de outubro, 2019.

Licenciamento: Este artigo é publicado na modalidade Acesso Aberto sob a licença Creative Commons Atribuição 4.0 (CC-BY 4.0), a qual permite uso irrestrito, distribuição, reprodução em qualquer meio, desde que o autor e a fonte sejam devidamente creditados. 